\title{
Investigation the Authenticity of Local and Imported Timber Species in Sri Lanka
}

\author{
Muthumala C.K. ${ }^{1^{*}}$ and Amarasekara H.S. ${ }^{2}$ \\ ${ }^{1}$ State Timber Corporation, Sampathpaya, Battaramulla, Sri Lanka \\ ${ }^{2}$ Department of Forestry and Environmental Science, Faculty of Applied Sciences, \\ University of Sri Jayewardenepura, Nugegoda, Sri Lanka \\ *ck_muthumala@yahoo.com
}

\begin{abstract}
In Sri Lanka there are over 400 different timber species, which show a remarkably wide range of variation in their physical properties as well as their anatomical structures. Hence timber Identification is a highly important task to confirm its authenticity.

The objective of this study is to investigate the authenticity of local and imported timber species used in Sri Lanka. In this study 237 timber identification reports (local and imported) were studied. These reports were issued by State Timber Corporation to various timber users and companies during past four years $(2007,2008,2009 \& 2010)$ after identifying the status of authenticity of timber samples.

According to timber identification reports, there were 118 local timber samples claimed by end users among 237 total samples. Out of 22 local timber species, it was found that 12 local timber species claimed by end users were $100 \%$ correct (authentic): Satin, Kumbuk, Batadomba, Mahogany, Pelen, Jak, Dawata, Hulanhik, Lunumidella, Sabukku, Bedidel and Kon. However claims for 10 local species were incorrect (not authentic). The claim for species Microcoris, Gammalu, Munamal, Ginisapu and Milla were not authentic in 100\%. Out of 28 timber species, there were only 6 imported timber species. In these samples, Bitis is the only timber species found with $100 \%$ of correct (authentic) end user claims. The claims for species Balau was totally incorrect. Authenticity percentages of Kandis, Tualang, Kempas and Red Balau were, 92, 77, 25 and 10 respectively.
\end{abstract}

According to the results, it can be concluded using of local species has higher authentic percentage compared to imported species.

Quality and authenticity of timbers used in Sri Lanka were also investigated using different timber samples collected from different construction sites in Western Province including large scale construction sites and house construction sites by a field survey conducted in Colombo district. 104 timber samples were collected from 68 construction sites randomly and claims for timber species by end users were also recorded.

According to the results, there were 28 timber species claimed by end users among 104 samples. Out of 28 timber species, it was found that 20 timber species claimed by end users were 100\% correct (authentic): which were Satin, Kumbuk, Paramara, Pinus, Hora, Microcoris, Domba, Margosa, Palu, Dawata, Hawarinuga, Lunumidella, Ginisapu, Milla, Grandis, Coconut, Bedidel, Kon, Ketakala and Kandis. However claims for 8 species were incorrect. The claim for species Jak was 93.3\% (15 samples) correct/authentic and the rest $6.7 \%$ (1 sample) was identified as Bedidel. The claim for species Mahogany was found with 
88.8\% authentic and the rest $11.2 \%$ ( 1 sample) was identified as Paramara. The claim for species Teak was found with $75 \%$ (3) authentic and the rest $25 \%$ (1) was identified as Paramara. The claim for species Liyan was found with $66.6 \%$ authentic.

Overall results indicated that out of 23 local timber species, the end user claims 19 local timber species were $100 \%$ correct/authentic. Among the 28 timber species investigated in the field survey, there were only 5 imported timber species out of which Kandis is the only timber species found with $100 \%$ of correct end user claims (all four samples have proven to be authentic). The calim for species Balau and Red Balau was totally incorrect. The sample was claimed as Balau was identified as Kandis and the samples of Red Balau (3 samples) was identified as Kandis (2) and Tualang (1). Authenticity percentages of Kempas and Taulang were $42.8 \%$ and $80 \%$ respectively. Based on overall results for imported timber species, it was found that out of five imported timber species, only one timber species claim was $100 \%$ correct/authentic. Based on the results of the present study it can be concluded that the end users get higher percentage of authentic local timber species compared to the imported species.

Keywords: Local timber, Imported timber, Authenticity 